\title{
Identification of a novel Drosophila gene, beltless, using injectable embryonic and adult RNA interference (RNAi) Svetlana Dzitoyeva, Nikola Dimitrijevic and Hari Manev*
}

Address: The Psychiatric Institute, Department of Psychiatry, University of Illinois at Chicago, Chicago, Illinois 60612, USA

Email: Svetlana Dzitoyeva - sdzitoyeva@psych.uic.edu; Nikola Dimitrijevic -ndimitrijevic@psych.uic.edu;

Hari Manev* - hmanev@psych.uic.edu

* Corresponding author

Published: 12 August 2003

BMC Genomics 2003, 4:33
Received: II June 2003

Accepted: 12 August 2003

This article is available from: http://www.biomedcentral.com//47I-2/64/4/33

(C) 2003 Dzitoyeva et al; licensee BioMed Central Ltd. This is an Open Access article: verbatim copying and redistribution of this article are permitted in all media for any purpose, provided this notice is preserved along with the article's original URL.

\begin{abstract}
Background: RNA interference (RNAi) is a process triggered by a double-stranded RNA that leads to targeted down-regulation/silencing of gene expression and can be used for functional genomics; i.e. loss-of-function studies. Here we report on the use of RNAi in the identification of a developmentally important novel Drosophila (fruit fly) gene (corresponding to a putative gene CG5652/GM06434), that we named beltless based on an embryonic loss-of-function phenotype.

Results: Beltless mRNA is expressed in all developmental stages except in 0-6 $\mathrm{h}$ embryos. In situ RT-PCR localized beltless mRNA in the ventral cord and brain of late stage embryos and in the nervous system, ovaries, and the accessory glands of adult flies. RNAi was induced by injection of short (22 bp) beltless double-stranded RNAs into embryos or into adult flies. Embryonic RNAi altered cuticular phenotypes ranging from partially-formed to missing denticle belts (thus beltless) of the abdominal segments A2-A4. Embryonic beltless RNAi was lethal. Adult RNAi resulted in the shrinkage of the ovaries by half and reduced the number of eggs laid. We also examined $\operatorname{Df}(\mathrm{I}) \mathrm{RK} 4$ flies in which deletion removes 16 genes, including beltless. In some embryos, we observed cuticular abnormalities similar to our findings with beltless RNAi. After differentiating $\operatorname{Df}(\mathrm{I}) \mathrm{RK} 4$ embryos into those with visible denticle belts and those missing denticle belts, we assayed the presence of beltless mRNA; no beltless mRNA was detectable in embryos with missing denticle belts.
\end{abstract}

Conclusions: We have identified a developmentally important novel Drosophila gene, beltless, which has been characterized in loss-of-function studies using RNA interference. The putative beltless protein shares homologies with the $C$. elegans nose resistant to fluoxetine (NRF) NRF-6 gene, as well as with several uncharacterized $C$. elegans and Drosophila melanogaster genes, some with prominent acyltransferase domains. Future studies should elucidate the role and mechanism of action of beltless during Drosophila development and in adults, including in the adult nervous system.

\section{Background}

RNA interference (RNAi) is a process that leads to targeted down-regulation/silencing of gene expression [1,2]. Typically, RNAi is triggered by double-stranded RNAs (dsRNAs) that are cleaved into small 21-23 bp small interfering RNAs by a dsRNA-specific enzyme, and thereafter, cellular machinery that causes degradation of dsRNA-complementary endogenous mRNA is set in motion. The physiological role of RNAi, particularly in the central nervous system (CNS), remains speculative [3], 
but the applicability of experimentally induced RNAi for functional genomics, i.e. loss-of-function studies, is becoming more apparent $[4,5]$.

Recently, we developed a method of dsRNA-injectable RNAi as a tool for loss-of-function studies in adult Drosophila (fruit fly) $[6,7]$ that combines loss-of-function phenotypes with neuropharmacological techniques [8]. Injectable RNAi has been successfully applied to adult honeybees [9], snails [10], and also to mice [11] and rats [12]. This method can be used both during various developmental stages of Drosophila, e.g., embryonic RNAi, as well as selectively in adult flies. In Drosophila, RNAi appears to be cell- and isoform-specific [13]. Whereas the GAL4-driven hairpin-induced RNAi can be cell autonomous [14], injecting adult Drosophila intra-abdominally with either long or short dsRNAs resulted in cell-nonautonomous silencing of the complementary endogenous mRNA and produced an altered phenotype [7]. Thus, these two methods of RNAi induction in Drosophila could be used as complementary experimental approaches; the injectable cell-nonautonomous RNAi appears preferable for studies of genes in which cell- or tissue-specificity of expression is unknown.

Previously, we demonstrated that injection into adult flies of dsRNA corresponding to a putative gene CG5652 (GM06434) destroys its cognate mRNA [6]. A homologue of this putative Drosophila gene has been characterized in C. elegans. Thus, Choy and Thomas [15] carried out a genetic screen for mutants that were resistant to a certain behavior, i.e., nose twitches, induced by antidepressant drugs such as fluoxetine (Prozac) (hence, "nose resistant to fluoxetine", NRF). However, in our work we did not observe any major behavioral effects of the fluoxetine in fruit flies, which precluded us from attempting to find the Drosophila correlate of fluoxetine-triggered nose twitches observed in C. elegans. This could be attributed in part to the failure of fluoxetine, whose mechanism of action involves binding to and inhibition of the serotonin transporter, to bind and inhibit the Drosophila serotonin transporter [16]. Moreover, these findings suggested to us that the CG5652 gene in Drosophila may have a different role from its putative homologue in C. elegans, and that this gene does not mediate behavioral actions of fluoxetine in fruit flies. Nevertheless, in pilot experiments with CG5652 gene silencing using injectable RNAi in adult flies, we observed an effect of RNAi on the spontaneous egg laying behavior of adult females [17].

In our present work, we used both embryonic and adult RNAi to further characterize this putative Drosophila gene. Our results indicate a developmental role for a novel gene that we named beltless based on the embryonic loss-offunction phenotype.

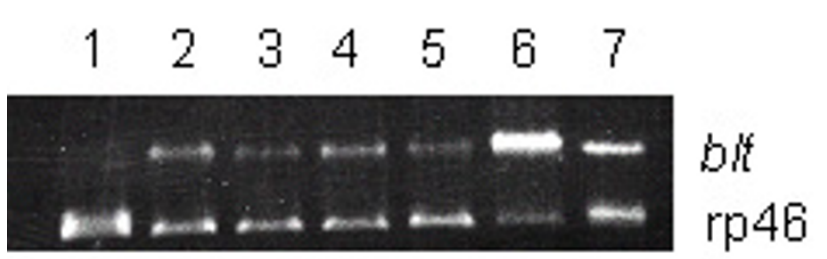

Figure I

Developmental expression of blt mRNA. The RT-PCR assay was performed with the total RNA extracted at different developmental stages. Shown are results from a typical experiment. Lane I: embryos, 0-6 h after egg laying (AEL); lane 2: late embryos (I7-I8 h AEL) and Ist instar larvae; lane 3: 2nd-3rd instar larvae; lane 4: pupae; lane 5: adult heads; lane 6: adult female body; lane 7: adult male body. Upper bands, blt mRNA; lower bands, ribosomal rp46 mRNA (control). Note the absence of blt mRNA in lane I, the early embryos.

\section{Results}

Blt mRNA is expressed at multiple developmental stages and in adult female and male Drosophila

To examine the expression of blt mRNA during Drosophila development, we conducted RT-PCR assays with total RNA isolated from 0-6 h embryos (early embryos), late embryos (stages 15-17), first to third instar larvae, pupae, and in the total RNA isolated from male and female heads and bodies. As shown in Fig. 1, we detected blt mRNA at all developmental stages except in the early embryonic stage.

We used in situ RT-PCR with digoxigenin-labeled dUTP to localize the distribution of blt mRNA expression in late embryos and observed a blt mRNA signal in the mesoectoderm at stages $8-11$. The signal was also localized in the invaginating pole cells and in the CNS (ventral cord and brain; stage 15-16) (Fig. 2A,2B). In situ hybridization with a digoxigenin-labeled antisense RNA was used to determine the spatial/tissue expression of the blt gene at other developmental stages, including in adult flies. In the third instar larvae, this assay localized blt mRNA expression in the area of the neuromuscular junctions of a subset of ventral body wall muscles and in the ring gland (Fig. $2 \mathrm{C}, 2 \mathrm{D}, 2 \mathrm{E}$ ). In adult flies, blt mRNA was found in the CNS (i.e., in the large neurosecretory cells and in interneurons), in the ovary (i.e., in the nucleated membrane sheath), surrounding the entire ovariole, in the corpus allatum (Fig $2 \mathrm{~F}, 2 \mathrm{G}, 2 \mathrm{H}$ ), and in the accessory glands of females and males (not shown). 

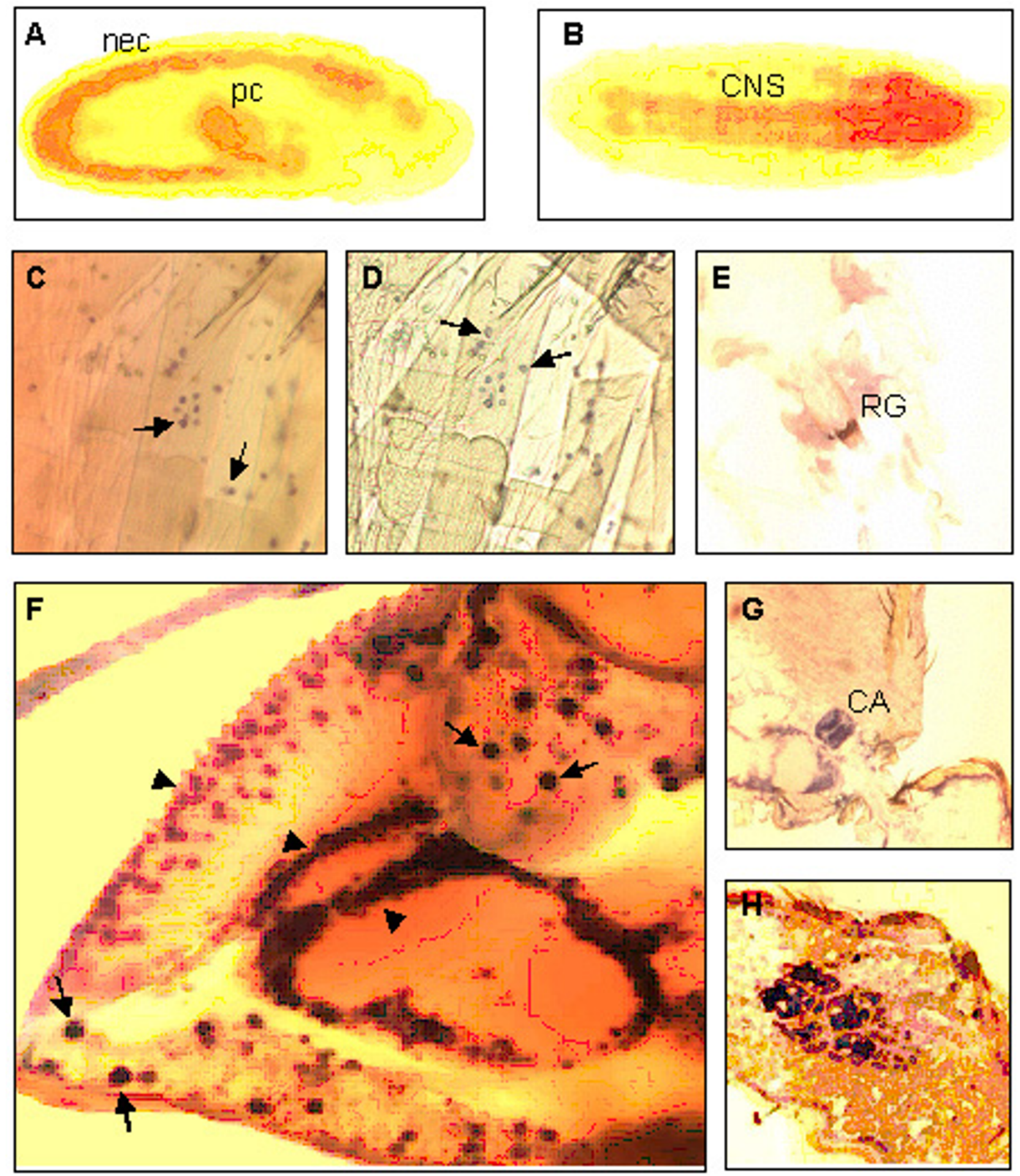

Figure 2

Localization of blt mRNA determined by in situ RT-PCR (A, B) and in situ hybridization with a digoxigeninlabeled blt riboprobe (C-H). In stage 8-II embryos, specific staining was observed in the neuroectoderm (nec) and in the invaginating pole cells (Pc) (A). In stage 15-16 embryos, specific staining appears in the developing central nervous system (CNS) (B). In the third instar larvae, blt mRNA is localized in neuromuscular junctions (C and D; arrows), and in the ring gland (RG) (E). (F-H) In adult flies, panel F shows blt mRNA localization in the interneurons of the optic lobe (arrowheads) and in the large cells (arrows), panel $G$ shows specific staining in the corpus allatum (CA) and panel $H$, in the ovary. 


\section{Beltless phenotype triggered by embryonic RNAi}

In this set of experiments, we injected syncytial blastoderm embryos with blt $d s R N A$ and staged the samples under mineral oil at $25^{\circ} \mathrm{C}$. Compared to control embryos injected with human 5-lipoxygenase $23 \mathrm{nt}$ dsRNA (there is no 5-lipoxygenase homologous gene in Drosophila), blt RNAi embryos appeared smaller and displayed a number of altered cuticular phenotypes ranging from partially differentiated cuticle to misdirected and only partiallyformed denticle belts, and to missing denticle belts (beltless) of the abdominal segment A2-A4 (Fig. 3). The blt RNAi embryos developed and moved around in the eggshell, but failed to hatch, indicating that the embryonic blt "knockdown" is lethal.

\section{Short 22 bp blt dsRNA injections into adult flies destroy endogenous blt mRNA}

The injection of short (22 bp) blt dsRNAs into adult Drosophila is effective in inducing blt-specific silencing; i.e., this type of RNAi led to the destruction of the blt mRNA assayed with RT-PCR (Fig. 4).

\section{Phenotype triggered by the adult blt RNAi}

In pilot studies, we observed a marked reduction of the number of progeny from females injected with either a long [6] or a short 22-nucleotide blt dsRNA. This observation was interesting because we observed in situ localization of blt mRNA expression in the ovaries (Fig. 2), leading us to a further characterization of ovarian morphology following blt dsRNA injection into adult female flies. In Drosophila, each ovary consists of a compact group of parallel ovarioles held together by a peritoneal sheath; each ovariole is surrounded by an epithelial sheath, which is a thin nucleated membrane. Seventy-two hours after injection, the ovaries of blt dsRNA-injected flies had shrunk to half the size of control dsRNA-injected flies, and the connections between the ovarioles were disorganized and loose (Fig. 5). Although ovarioles of blt dsRNAinjected flies contained the proper number of egg chambers, their appearance was altered, suggesting that the maturation rate of the eggs might have slowed down (Fig. $5)$.

As a measure of ovarian function, we tested the effects of blt RNAi on oviposition (egg laying behavior). Table 2 shows that the injection of control dsRNA into adult females did not alter oviposition, whereas injection of blt dsRNA, which altered ovarian morphology (Fig. 5), significantly reduced the number of eggs laid.

\section{Blt mutants}

The Blt gene is localized in region 13B1 of the X chromosome (see below). Insertion/deletion mutagenesis screens of the Drosophila X chromosome revealed several key developmental genes associated with embryonic/first instar larval cuticle development [18]. These genes are also recessive-lethal and have been assigned to loci $11 \mathrm{~A}$ 13B1. To test whether a deletion of blt results in an embryonic phenotype similar to that produced by embryonic blt RNAi, we examined flies carrying a deficiency on the $\mathrm{X}$ chromosome region 13A9-B1; i.e., Df(1)RK4 flies. In this strain, deletion removes 16 genes, including blt. In some embryos (about 3\%) of these flies, we observed cuticular abnormalities similar to our findings with blt RNAi (Fig. $6)$. For example, we observed that the denticle belt is typically either interrupted or missing from the abdominal A4 segment. In a large number of embryos, the phenotypical changes are more severe; for example, denticle belts have not been formed at all. However, even in these severe cases, the mouth hook formation is not affected (Fig. 6). In this mutation, we observed extensive embryonic lethality.

After differentiating the Df(1)RK4 embryos based on their blt phenotype into two groups; i.e., those with visible denticle belts and those missing denticle belts, we assayed the presence of blt mRNA. No blt mRNA was detectable in embryos with missing denticle belts (Fig. 7).

\section{The predicted structures of the blt gene and protein}

According to a computer search and analysis of the available sequence data bases of the Drosophila genome (Berkeley Drosophila Genome Project; BDGM), the blt gene is located on the X chromosome and has been mapped cytologically to region 13B1 (FlyBase report for CG5652; http://flybase.bio.indiana.edu). The mRNA transcript from CG5652-RA is 2069 nt; the genomic sequence encompasses about $3.7 \mathrm{~kb}$ and comprises 7 exons (Fig. 8A). Our Northern blot hybridization analysis of blt mRNA from total RNA extracted from adult Drosophila identified a single band of about $2 \mathrm{~kb}$ (Fig. 8B).

The predicted blt gene mRNA encodes 659 amino acids (Q9VXX9, NM_167430). The PROSITE [19,20] motif search for Blt predicts potential phosphorylation sites for CAMP- and cGMP-dependent protein kinases, protein kinase $\mathrm{C}$, and tyrosine kinase (Fig. 9A). In addition, the blt gene contains possible amidation, N-glycosylation, and three N-myristoylation sites. The primary sequence and hydrophobicity profile of the Blt protein reveals 7 transmembrane domains and regions with low complexity composition. A BLAST homology search aligned the protein with several uncharacterized C. elegans and Drosophila genes with acyltransferase domains (Fig. 9B).

\section{Discussion}

Using embryonic and adult RNAi, we have identified a loss-of-function phenotype for a novel Drosophila gene. Both embryonic RNAi and a mutation/deletion of this gene, e.g., Df(1)RK4 flies, are embryonic lethal and result 

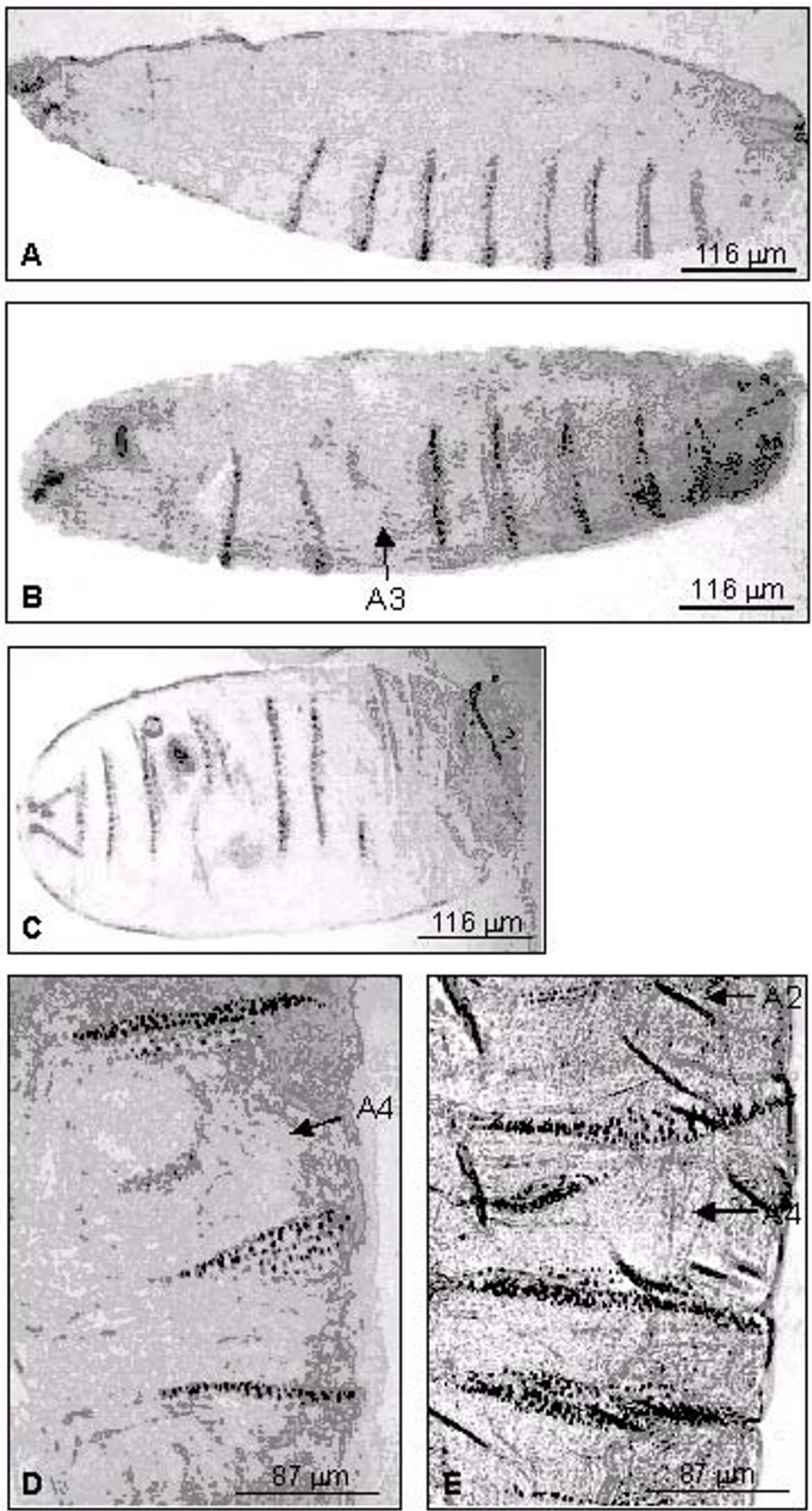

Figure 3

Embryonic blt RNAi induces a prominent cuticular phenotype. (A) A control embryo, injected with a human 5-lipoxygenase 22 bp dsRNA; (B-E) embryos injected with blt dsRNA. RNAi induced phenotype: Panels $B$, D and E show missing or interrupted denticle belts from the abdominal segments $A 2, A 3$ and $A 4$ (arrows). Panel $C$ shows an example of a more severe cuticular phenotype. 


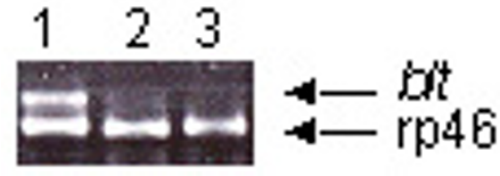

\section{Figure 4}

Adult blt RNAi, triggered by injections of blt dsRNA into the abdomen of adult female flies. RT-PCR assay was performed 4.5 days after injections. Lane I: control, lane 2: blt dsRNA ( $100 \mathrm{ng} / \mu \mathrm{l})$, lane 3: blt dsRNA $10 \mathrm{ng} / \mu \mathrm{l}$. Upper bands, blt mRNA; lower bands, ribosomal rp46 mRNA. Note the absence of blt mRNA in lanes 2 and 3.

in visible cuticular abnormalities, mainly the disappearance of abdominal A2, A3 or A4 denticle belts, hence the name beltless. In addition to this evidence for a developmentally crucial role for $b l t$, a selective silencing of blt in adult female flies resulted in prominent abnormalities of the ovaries and eggs.

The lack of some but not all denticle belts suggest that blt could participate in the functioning of cis-regulatory elements in the denticle pattern formation cascade. Possibly this function of blt could take place downstream of Hox transcription factors, which are the prime Drosophila segmental morphology identifiers. Thus, secreted signaling proteins Wingless $(\mathrm{Wg})$ and Hedgehog $(\mathrm{Hh})$ are essential for establishing the denticle pattern in the epidermis of Drosophila embryos. In the embryonic epidermis, these proteins regulate the expression of Ser and rho, which are critical for the final steps of denticle formation [21,22].

In this process, secondary modifications of signaling proteins may be crucial for the biological activity of these proteins. For example, the Hh protein undergoes autocatalytical cleavage by its own C-terminal domain, which produces the Hh signaling peptide. The cleavage of $\mathrm{Hh}$ is followed by the addition of cholesterol to the C-terminal end of its signaling protein $[23,24]$. On the other hand, the N-terminal of this protein is modified by an acyltransferase named skinny hedgehog (Ski). Ski, which is a member of a group of segment polarity genes, is required for Hh activation by palmitoylation of the $\mathrm{N}$-terminal [25]. Alternatively, the N-terminal of the Hh signaling protein can be modified by the Rasp protein, another member of the segment polarity genes that is catalytically active as an acyltransferase [26].

Interestingly, the primary sequence and hydrophobicity profile of the Blt protein suggest that this is a membraneassociated protein with 7 transmembrane domains, whereas its homology with several uncharacterized C. elegans and Drosophila genes with acyltransferase domains suggests that Blt could possess acyltransferase activity. These characteristics point to putative similarities between blt and other segment polarity genes. This possibility is further supported by our findings of the blt loss-of-function embryonic phenotype, and we postulate that the putative acyltransferase activity of blt may be needed for Hh activation in anterior abdominal segments A2-A4. Namely, after blt RNAi, we did not observe embryos with missing A1 or A5-A8 denticle belts.

Based on our characterization of the localization of embryonic blt mRNA, i.e. in the neuroectoderm, CNS, and the invaginating pole cells, an additional developmental role for blt should be considered. Developmental blt expression also includes the ring gland, which degenerates during metamorphosis and produces hormones that participate in molting and metamorphosis. The embryonic lethality of blt RNAi and blt deletion also point to a putative crucial developmental function of this gene.

The selective use of blt RNAi in adult flies enabled us to investigate blt loss-of-function phenotype in adult Drosophila. Thus, in addition to the embryonic beltless phenotype, we observed that blt silencing produces a major disruption in egg development and maturation in adult females. Whether the putative acyltransferase activity of blt participates in the adult loss-of-function phenotype should be investigated.

Localization of blt mRNA in the nervous system of developing and adult Drosophila indicates a possible role for Blt in neuronal development and functioning. As indicated above, the primary sequence and hydrophobicity profile of the Blt protein suggests 7 transmembrane domains and regions with low complexity composition. There was no evidence for an $\mathrm{N}$-terminal signal sequence; this would classify Blt as a type III membrane protein typically found in endoplasmic reticulum Golgi bodies. Furthermore, the predicted amino acid composition of Blt suggests similarities to the peroxisome microbody. Peroxisomes belong to the microbody family of organelles and peroxisomal proteins are crucial for neuronal development; defects of peroxisomal assembly factors lead to severe neurological diseases known as peroxisome biogenesis disorders [27]. The peroxisomal signal motif N/T/K/KL (PTS1; the peroxisome-targeting signal 1) [28] was found at the C-terminal end of Blt protein.

Found in neural cell peroxisomes [29], acyltransferase activity is important during insect development, particularly in the larval synthesis of triacylglycerols and phosphoglycerides [30]. Acyltransferase activity also appears to be important for Drosophila synaptic vesicle 

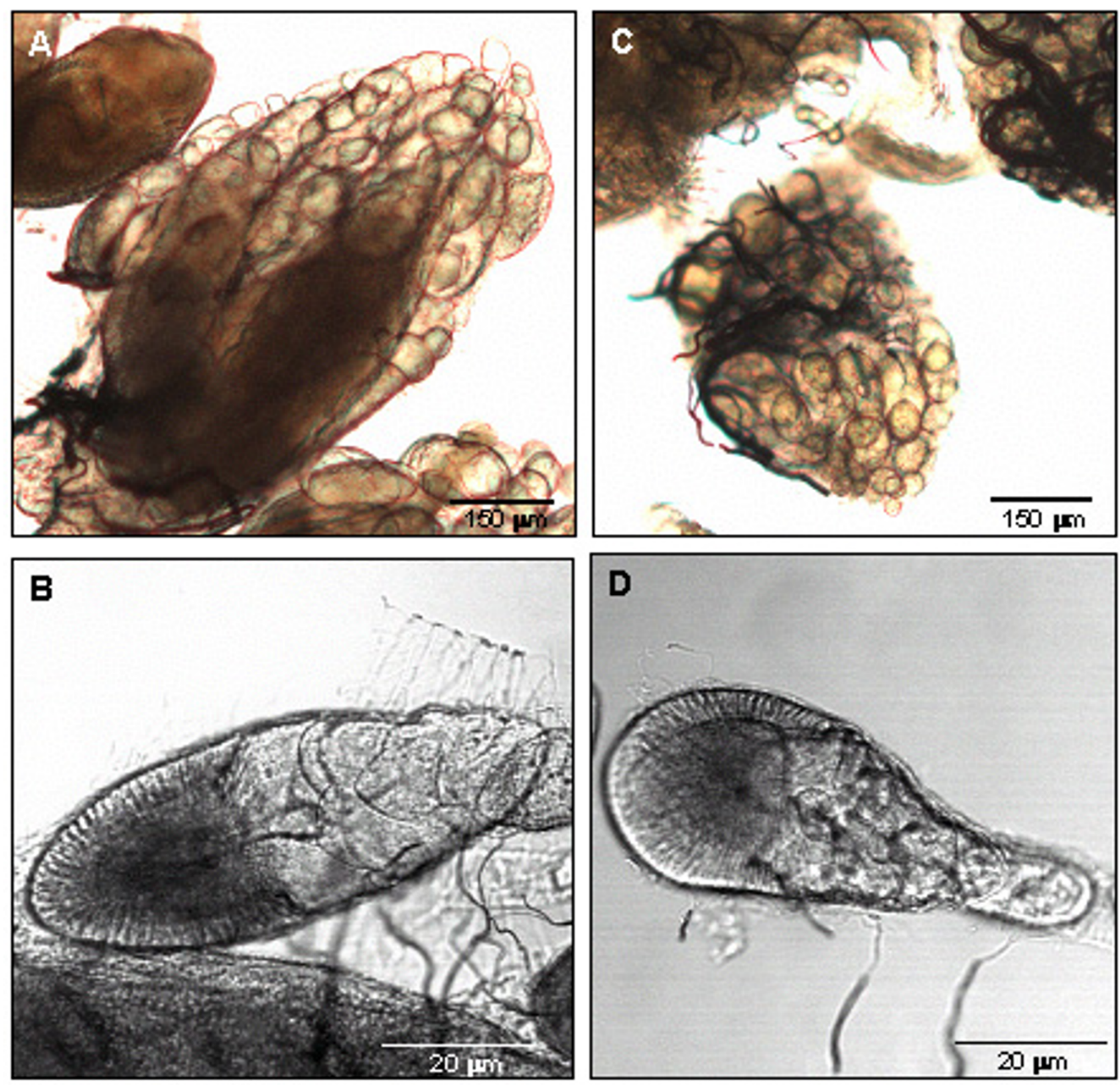

\section{Figure 5}

Adult blt RNAi-induced alterations of ovarian morphology. (A) Control ovary isolated from flies injected with a human 5-lipoxygenase 22 bp dsRNA. (B) Confocal microscopy of a control developing egg. (C) Ovary isolated from flies injected with blt 22 bp dsRNA. (D) Confocal microscopy of a blt RNAi developing egg. Note the smaller size and presence of deformities in the ovaries and eggs in $C$ and $D$, respectively. 
Table I: Oligonucleotides used for the synthesis of blt dsRNAs

\begin{tabular}{ll}
\hline T7 promoter (bold letters) Targeted cDNA sequence (22 $\mathbf{n t})$ \\
\hline Sense & 5'-TAATACGACTCACTATATGCGCCGATCGCCTGGTGTTT-3' \\
Antisense & 5'-AAACACCAGGCGATCGGCGCATATAGTGAGTCGTATTA-3' \\
Sense & 5'-TAATACGACTCACTATAAAACGCGGCTAGCGGACCACA-3' \\
Antisense & 5'-TGTGGTCCGCTAGCCGCGTTTTATAGTGAGTCGTATTA-3' \\
Sense & 5'-TAATACGACTCACTATGGTCATTGGACGAGCTGCCTCC-3' \\
Antisense & 5'-GGAGGCAGCTCGTCCAATGACCTATAGTGAGTCGTATTA-3' \\
Sense & 5'-TAATACGACTCACTATACCAGTAACCTGCTCGACGGAGG-3' \\
Antisense & 5'-CCTCCGTCGAGCAGGTTACTGGTATAGTGAGTCGTATTA-3' \\
\hline
\end{tabular}

Table 2: Inhibitory effect of adult blt RNAi on oviposition $72 \mathrm{~h}$ after injection

\begin{tabular}{ll}
\hline Treatment of adult females & $\begin{array}{l}\text { Number of eggs laid/fly/24 h } \\
\text { (mean } \pm \text { s.e.m.) }\end{array}$ \\
\hline Control I (buffer injection) & $8.7 \pm 0.7$ \\
Control 2 (dsRNA injection) & $8.3 \pm 0.7$ \\
blt dsRNA injection & $4.8 \pm 0.6^{*}$ \\
\hline
\end{tabular}

$* \mathrm{P}<0.00 \mathrm{I}$ (Dunnett's test; $\mathrm{n}=2 \mathrm{I}$ )

budding at the neuromuscular junction [31] and in general, is involved in synaptic vesicle biogenesis [32]. Interestingly, we found prominent blt mRNA presence in the neurite-like structures at the neuromuscular junctions of the larvae. It has recently been proposed that the dendritic localization of mRNAs underlies certain aspects of synaptic plasticity [33].

Finally, acyltransferase activity was found in insect ovaries [34] where we also observed significant blt expression. Based on our RNAi experiments in adult flies, the presence of Blt in the ovaries appears to be functionally important and the loss-of-function phenotype in adult flies included both morphological and functional (e.g., oviposition) alterations and deficits. It is possible that these phenotypes are a reflection of an essential function of Blt in the corpus allatum, which releases the juvenile hormone that regulates egg maturation, as well as of Blt in the surrounding epithelial sheath in the ovariole.

\section{Conclusions}

In conclusion, we identified a novel Drosophila gene that we named beltless. Our results demonstrated that blt is crucial during oogenesis and embryogenesis. The expression of blt in the adult nervous system suggests that besides its developmental role blt might be important for neuronal functioning. Further studies are needed to fully characterize this novel gene.

\section{Methods \\ Fly stocks and injections}

Wild type Drosophila melanogaster (CS/S) flies and Df(1)RK4 mutant flies (Bloomington Drosophila Stock Center, Donors: Robert Kreber and Rachel Drysdale) carrying a deficiency of the $\mathrm{X}$ chromosome region 13A9B1 were cultured at $25^{\circ} \mathrm{C}, 50-60 \%$ humidity, $12 \mathrm{~h} / 12 \mathrm{~h}$ light/dark cycle, on yeast, dark corn syrup, and agar food. For the injections, flies were anesthetized whit $\mathrm{CO}_{2}$ (at a maximum of $5 \mathrm{~min})[6,7]$. Using custom-beveled glass pipettes $(20 \times 40 \mu \mathrm{m}$ tip diameter) coupled to a cell injector (Narashige IM-200) and a micromanipulator under a stereo microscope (Leica GZ6), we injected a volume of $0.2 \mu \mathrm{l} /$ fly by a pulse pressure of $300 \mathrm{kPa}[6,7]$. Injection of embryos was performed using the Nanoliter 2000 injector (World Precision Instruments).

\section{dsRNA synthesis}

For RNAi studies, we targeted two 22-nucleotide long regions of the blt gene; i.e., regions 2-23 and 685-708. Eight 39-mer DNA oligonucleotides with an attached T7 RNA polymerase promoter sequence were synthesized (Integrated DNA Technology, Inc.); these oligonucleotides represented both sense and antisense strands. The sequences of the sense and antisense DNA oligonucleotides corresponding to the blt gene used for the in vitro transcription reaction are shown in Table 1; only one match was found in the genome database pattern search analyses for each chosen targeted sequence.

One set of oligonucleotides produced dsRNA probes with a 3 'overhanging 2 UUnt, and a second set was used for the production of blunt-end dsRNAs with GG..CC flanking nucleotides. Equal amounts of oligonucleotides were annealed to form a double-stranded template by heating at $80-85^{\circ} \mathrm{C}$ for $5 \mathrm{~min}$ and cooling down on ice. The in vitro transcription reaction ( $30 \mu \mathrm{l}$ volume) for the synthesis of the $22 \mathrm{nt}$ RNA run of transcripts contained 0.1 $\mu \mathrm{g}$ of a template, $500 \mu \mathrm{M}$ each CTP, GTP, ATP, and UTP, $1 \times$ transcription buffer (Tris- $\mathrm{HCl}, \mathrm{pH} 7.5,10 \mathrm{mM}$ dithiothreitol, $1 \%$ bovine serum albumin), $20 \mathrm{U}$ of 

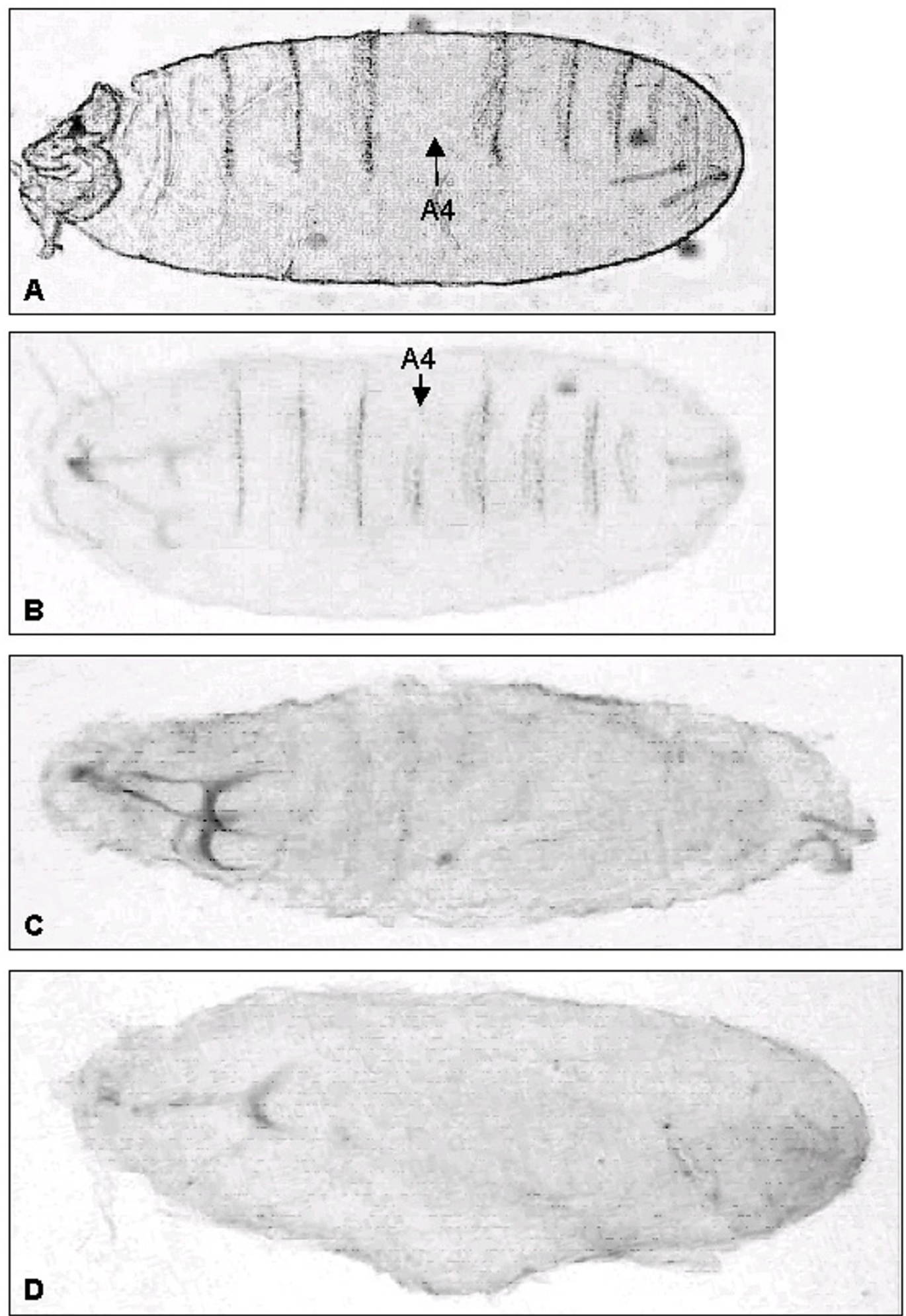

\section{Figure 6}

Df(I)RK4 embryonic cuticular phenotype. In this mutation, the denticle belt is missing from the abdominal A4 segment (A), or is interrupted (B) (arrows). (C, D) In a large number of embryos, the phenotypical changes are more severe; for example, no denticle belts are formed; panel C: dorsal view. However, even in these severe cases, the mouth hook formation is not affected (panel D, ventral view). 


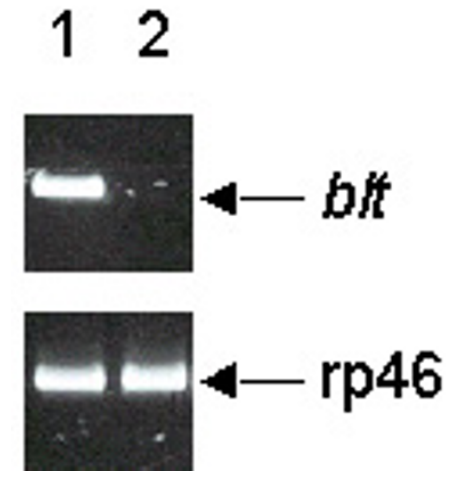

\section{Figure 7}

The absence of blt mRNA in the Df(I)RK4 embryos with missing belts. Shown are the RT-PCR products from the total RNA extracted from embryos with normal denticle patterns (lane I) and embryos with missing belts (lane 2). Upper panel, blt mRNA; lower panel, corresponding rp46 mRNA.

RNAse inhibitor, and $50 \mathrm{U}$ T7 RNA polymerase (Gibco $\mathrm{BRL}$ ). The reactions were carried out at $37^{\circ} \mathrm{C}$ for $1 \mathrm{~h}$. The RNA molecules were annealed together in heat denaturing conditions $\left(65^{\circ}-70^{\circ} \mathrm{C}\right.$ for $\left.5 \mathrm{~min}\right)$ and placed on ice. The quality of both RNA and DNA oligonucleotides was analyzed on $6 \%$ NuSive agarose gel (Sigma). As a negative control, we used dsRNA that targeted the human 5-lipoxygenase gene because Drosophila does not have any lipoxygenase homologues. The following is the cDNA sequence of a $22 \mathrm{nt}$ of the human 5-lypoxygenase gene template that we used for in vitro dsRNA synthesis: 5'-ttcatgcacatgttccagtctt-3'; no match was found in the Drosophila genome database pattern search analyses.

To find an effective concentration of dsRNA for the RNAi studies, we tested four different dsRNA concentrations in pilot experiments; dsRNA was injected intra-abdominally into the males and females: $1 \mu \mathrm{g} / \mu \mathrm{l}, 0.5 \mu \mathrm{g} / \mu \mathrm{l}, 0.1 \mu \mathrm{g} / \mu \mathrm{l}$, and $10 \mathrm{ng} / \mu \mathrm{l}$ in injection buffer $(0.1 \mathrm{mM}$ sodium phosphate, pH6.8, $5 \mathrm{mM} \mathrm{KCl})(16.8-0.16$ pmol, respectively). The most effective and longest lasting (5 days) silencing effect was detected with the lowest concentration of dsRNA (i.e., $10 \mathrm{ng} / \mu \mathrm{l}$ ) for both probes, and we used this concentration in all subsequent experiments, except one experiment that was conducted with $100 \mathrm{ng} / \mu \mathrm{l}$ (where indicated).

\section{Reverse transcription-polymerase chain reaction (RT- PCR)}

To determine the presence of endogenous blt mRNAs and the effect of RNAi, we used an RT-PCR assay [6]. The total
RNA was extracted from samples collected at different stages of Drosophila development. For adult flies, the total RNA was extracted separately from the heads and bodies of male and female flies; two flies were used for each experiment. Two embryos displaying cuticular defects and two normal embryos from Df(1)RK4 flies were used for RT-PCR. RNAs were DNAase treated prior to RT reaction. The rp49 gene was used as an internal control. The following are the primers used in the RT-PCR assay: for blt direct 5'-atcgatacggaactcttgcgt-3', reverse 5'-atttcgctggggatcactaaac-3'; for rp49 - direct 5'-atgaccatccgcccagcataca-3', reverse 5'-tgtgtattccgaccaggttac-3'. The reaction conditions were as follows: first strand synthesis, $1 \mathrm{~h}$ at $37^{\circ} \mathrm{C}$ in $20 \mu \mathrm{l}$ of reaction mix with a $0.2 \mathrm{mM}$ of each dNTPs, 10 pmol of a hexanucleotide primers, 20 U RNAse inhibitor, and $100 \mathrm{U}$ reverse transcriptase. We performed 30 cycles of PCR in $20 \mu \mathrm{l}$ of reaction mix at the following conditions: $92^{\circ} \mathrm{C}$ for $30 \mathrm{sec}, 60^{\circ} \mathrm{C}$ for $30 \mathrm{sec}, 72^{\circ} \mathrm{C}$ for 30 sec. Agarose gel electrophoresis was used to resolve and visualize the PCR reaction products.

\section{Northern blot assay}

Total RNA was extracted from the heads and bodies of male and female flies with a Trizol reagent (Gibco BRL). Ten micrograms of total RNA per sample were analyzed according to a standard protocol for the Northern blot analysis [35]. A digoxigenin-labeled 524 bp PCR fragment of blt was used as the hybridization probe. The signal was detected via chemiluminescence with the CSPD reagent ( $a$ substrate for alkaline phosphatase; Roche, catalog number 1655884); the blots were exposed for $12 \mathrm{~h}$ to Kodak BioMax film.

\section{In situ hybridization assay of blt mRNA}

The heads of 20-30 male and female flies were collected $72 \mathrm{~h}$ after injection with dsRNA oligonucleotides or ringer solution, and heads from naïve flies were also collected. The heads were sliced on dry ice with a sterile surgical blade (\#11) and transferred into the tubes with a fixation buffer (15\% formaldehyde in phosphate-buffered saline; PBS; pH 7.4) for $20 \mathrm{~min}$. Ovarian, corpus allatum, and ring gland hybridization was done on cryostat sections of female flies and 3rd instar larvae. For the 3rd instar larval muscle preparation, larvae were dissected from the ventral side with a surgical blade (\#11), the cuticle was stretched and pinned down, and the preparations were fixed. The ovaries also were collected from anesthetized flies for confocal microscopy (Leica TCS-NT 1.6.587) without the in situ hybridization. They were manually dissected in PBS and fixed in a 1\% glutaraldehyde in PBS buffer for $20 \mathrm{~min}$, rinsed in PBS, and mounted in a $\mathrm{NaCl} /$ glycerol solution.

The in situ hybridization procedure was applied as described elsewhere [36]. Briefly, the samples were incubated with proteinase $\mathrm{K}(10 \mu \mathrm{g} / \mathrm{ml})$ for $5 \mathrm{~min}$ at room 
A

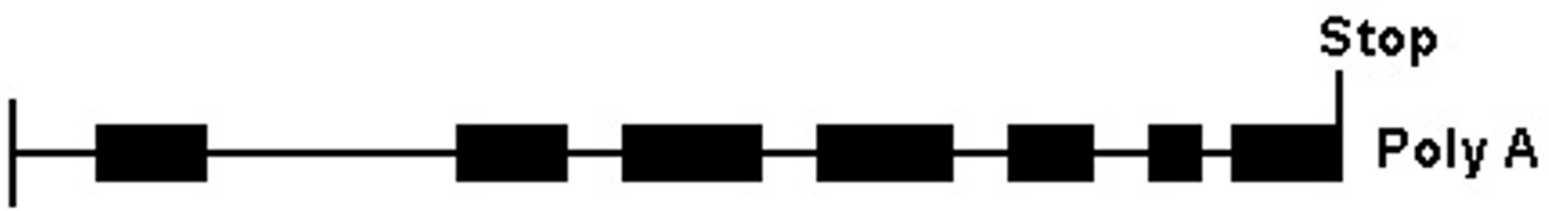

B

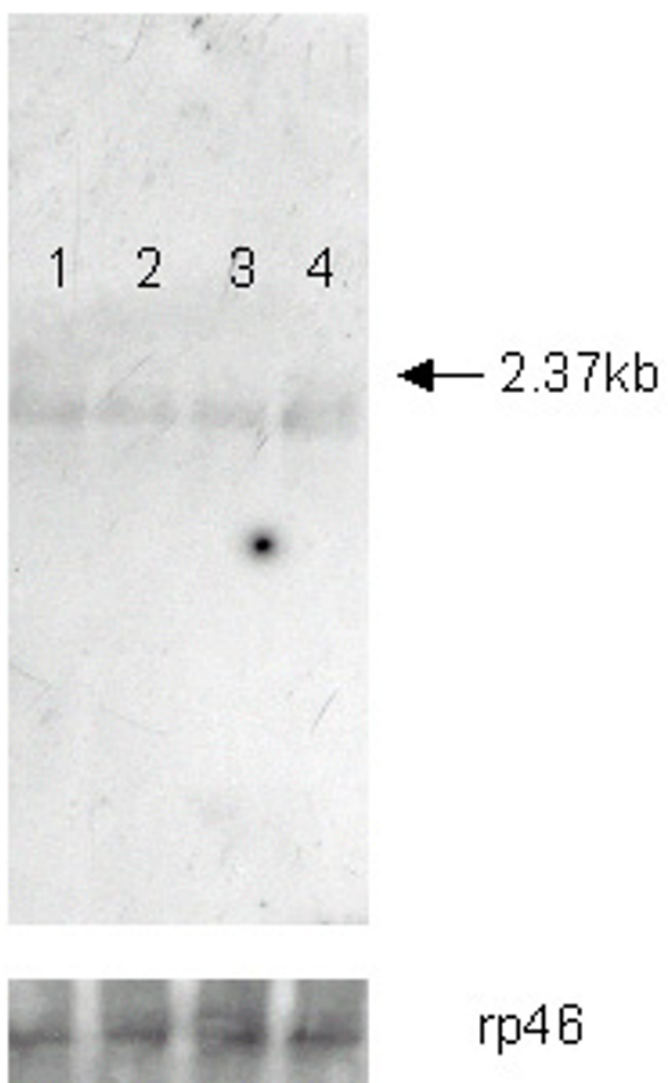

\section{Figure 8}

The exon/intron structure of the blt gene and Northern blot analysis. (A) Exons: filled squares, introns: lines. (B) Northern blotting revealed a single band (the arrow indicates the $2.37 \mathrm{~kb}$ marker size), visualized with digoxigenin-labeled probe, using the total RNA extracted from heads and bodies of male and female flies. Lane I: female body, lane 2: male body, lanes 3 and 4: their respective heads. The lower panel shows the corresponding ribosomal rp46 mRNA. 
A

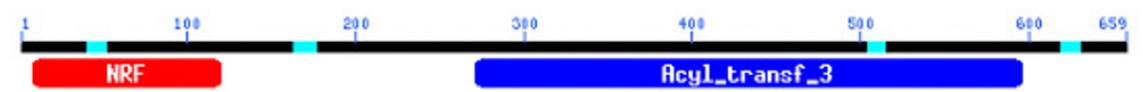

NRF, N-terminal domain in C. elegans NRF-6 (Nose Resistant to Fluoxetine-6)

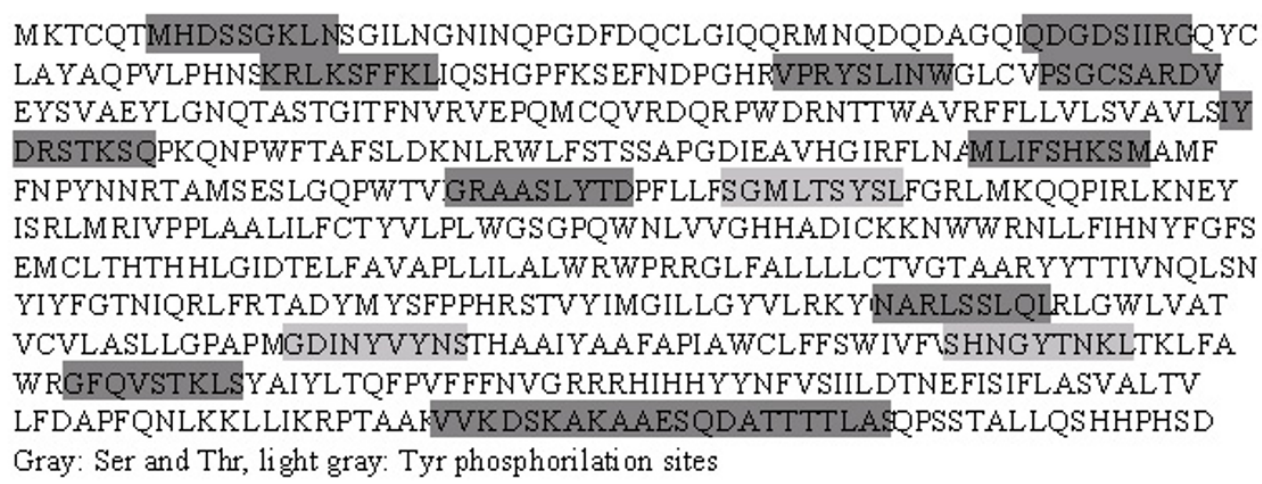

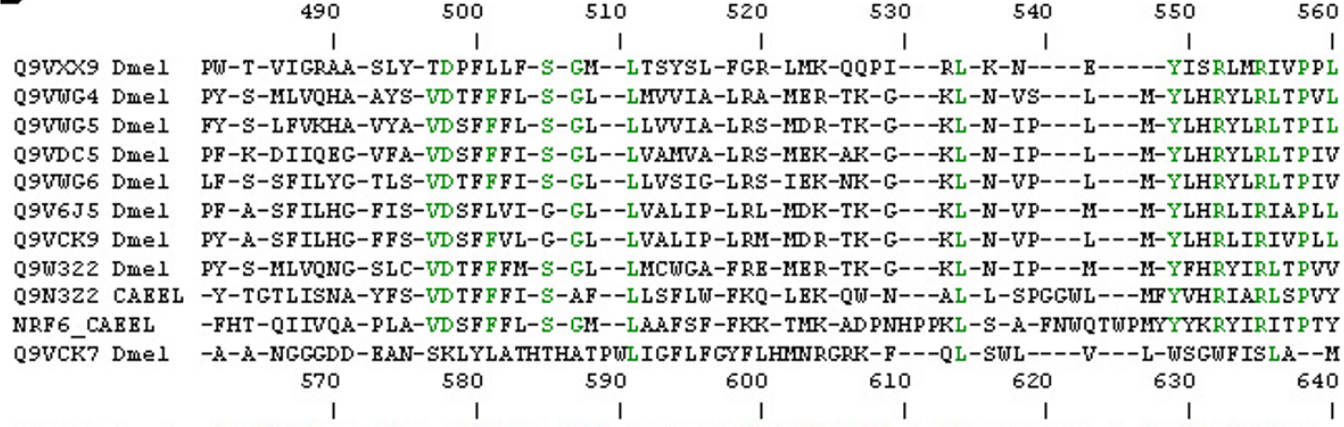
Q9VXX9 Dmel -AALI-LFCTYVLPLU-G-SGP-Q--TNL-VVGHHADICKRNT-WRNLL-F IHNYF-GFSEM--C-LTHTHHLGIDT-E-

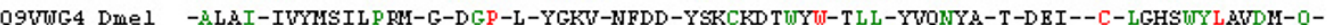
Q9VWG5 Dmel -AIAI-L FMIRIL PLU-E-SGP-L-KGSI-SFDD-YSACESTWYW-TLL-YVQNYA-T-DSL--C-LSHSWYLAVDM-Q-

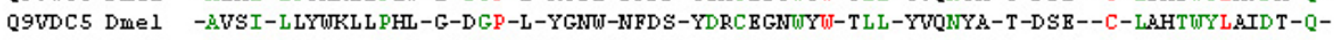
Q9VUG6 Dmel -AVAI-LAFYKMIPLI-A-DGP-M-YDDI-GFFD-YSGCKMTUYW-TLL-YVQNYA-T-SDV--C-VPHTUYLAVDM-QQ9V6J5 CAERL -MMAI-VUHMLLMPLI-S-SGP-L-FVG--GYIG-NSACKAGWYU-TLL-FUNNY--T-DAK--C-LAQQSTYLSLDM-QQ9VCK9 CAEEL -ALIA-VMYLLMP TV-A-DGP-R-FGS--GYSG-TWDCENGWYU-TLL-FUNNY--T-EEK--C-LGHTUYLSVDM-QQ9W322 Dmel -AVVV-LYMSLYKYS-G-AGP-MWF-KL-GTQD--KRCADTW-WATLI-YVQNYA-F PYSI--C-ISQSWYLAVDT-QQ9N3Z2 CAERL -YVTI-LFFTFVFT PSNV-DMP-A-FMTP-AVUD--DTCQNSY-WVNLL-YIQNIV-GPKDI--C-YFISWYLATDL-QNRF 6_CAEEL -IIVM-LFDTLFTYI-S-NGP---FWRP-IERQ---GCSIAWT-WTNLI-YLNNFL-L-QDQECC-MGWTUYLANDM-QF Q9VCK 7 Dmel -IFTS-IF-A-TYPSA-KWSAPPL--STLDESLY-YTL-TRVG-WPLAMCUV-VFUCI-QGY--CGLANS-FLSTPLWQ-

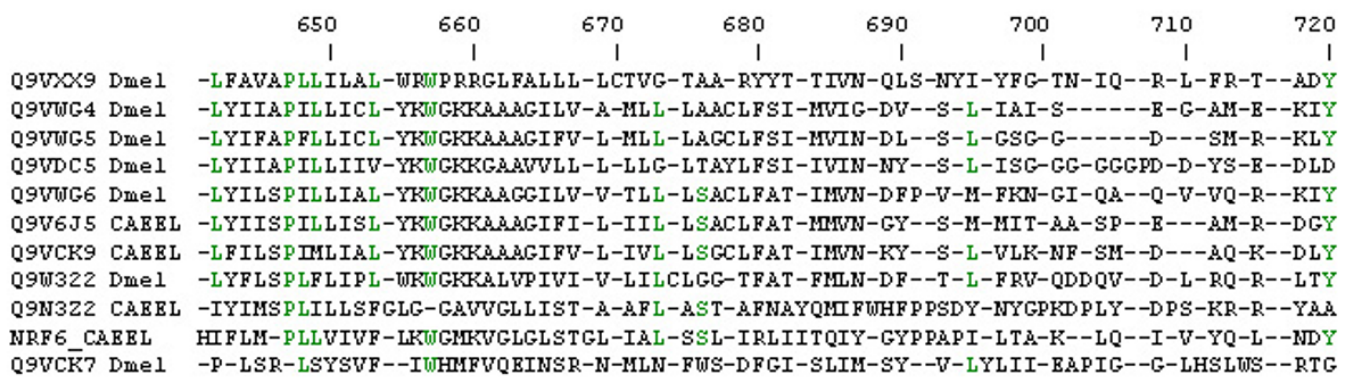

\section{Figure 9}

The putative beltless protein; analysis and multiple alignment. (A) The putative beltless (Blt) protein shares homologies with the $C$. elegans nose resistant to fluoxetine (NRF) NRF-6 gene, including the NRF domain and the acyltransferase domain (Acyl_transf_3). Using the PROSITE motif search engine, we found a high probability for multiple potential phosphorylation sites in the putative Blt (shaded rectangles). (B) The BLAST homology search and the CLASTLOW multiple alignment tools aligned the Blt protein (Q9VXX9) with several uncharacterized C. elegans and Drosophila melanogaster genes, some with prominent acyltransferase domains. 
temperature, rinsed with a glycine $(2 \mathrm{mg} / \mathrm{ml})$ in PBS, and prehybridized (6x SSC, i.e., $3 \mathrm{M} \mathrm{NaCl}, 0.3 \mathrm{M}$ sodium citrate, $10 \mu \mathrm{g} / \mathrm{ml}$ sonicated salmon sperm DNA, $10 \mu \mathrm{g} / \mathrm{ml}$ yeast tRNA, $50 \%$ formamide, $0.01 \%$ Tween-20) at $55^{\circ} \mathrm{C}$ for $1 \mathrm{~h}$. The samples were hybridized overnight at $55^{\circ} \mathrm{C}$ with digoxigenin-UTP-labeled (Roche) sense and antisense strands of a $524 \mathrm{bp}$ fragment of blt gene (sequence 128-652; AF 173374). They were washed three times in PBS, $1 \mathrm{~h}$ each at $55^{\circ} \mathrm{C}$, and incubated with anti-digoxigenin antibody conjugated with alkaline phosphatase (1:1000 in PBS at room temperature for $1 \mathrm{~h})$. Thereafter, sections were washed 4 times 30 min each in PBS at room temperature, and rinsed twice in a blue color development buffer for alkaline phosphatase $(100 \mathrm{mM}$ $\mathrm{NaCl}, 100 \mathrm{mM}$ Tris-HCl, pH 9.5, $50 \mathrm{mM} \mathrm{MgCl}{ }_{2}, 0.1 \%$ Tween-20). The color was developed with NBT/BCIP (nitroblue tetrazolium/5-bromo-4-chloro-3-indolyl phosphate; Roche) and the reaction was stopped with 2 $\mathrm{mg} / \mathrm{ml}$ glycine in PBS, $\mathrm{pH}$ 2.2. Samples were mounted in a mounting solution ( $80 \%$ glycerol, $0.25 \mathrm{mM} \mathrm{NaCl}$ ) and images were taken under the microscope.

Since we were not able to detect mRNA staining in embryos with conventional in situ hybridization (probably because the signal is below detection level), we used an in situ RT-PCR assay with digoxigenin-labeled dUTP to localize $b l \mathrm{t}$ mRNA in the embryos. Briefly, the 0-20 h embryos were collected on agar plates and fixed and processed as described elsewhere [36]. The RT step was carried out with at least 200 embryos per tube and in $20 \mu \mathrm{l}$ of digoxigenin-labeling PCR mix (Roche); the samples were processed for 10 cycles $\left(92^{\circ} \mathrm{C} 15 \mathrm{sec}, 57^{\circ} \mathrm{C} 30 \mathrm{sec}, 72^{\circ} \mathrm{C}\right.$ $30 \mathrm{sec})$. Thereafter, they were washed several times in PBT (PBS/Tween-20), incubated with anti-digoxigenin antibody conjugated with alkaline phosphatase $(1: 1000$ in PBS) for $30 \mathrm{~min}$, and washed in PBS for $2 \mathrm{~h}$. Specific primers used in this PCR reaction were as follows: direct5'-tagtcggctgatgaggattgttcc-3', reverse-5'-acacgtagttgatgtcacccatgg-3'. As a negative control, either one or both primers were omitted from the above-described procedure.

\section{Cuticle preparation}

Embryos were manually dechorionated, covered with mineral oil on a glass slide, and flattened with a cover slip. They were steam-fixed on top of boiling water for $1 \mathrm{~min}$, the cover slips were slowly removed and the mineral oil was replaced with a mounting solution (glycerol/ $\mathrm{NaCl}$ ). The vitteline membrane and all debris were manually removed and covered with a cover slip. The preparations were examined under a microscope and photographed.

\section{Oviposition}

Mated female flies were injected with $10 \mathrm{ng} / \mu \mathrm{l}$ of $b l t$ dsRNA, control dsRNA, or with buffer and individually placed for $24 \mathrm{~h}$ into small glass tubes with food. Flies were transferred to new tubes every 24 hours. The tubes were inspected under the microscope and the number of eggs laid was counted.

\section{Author's contribution}

SD carried out the molecular studies, analyzed the predicted structures of the blt gene and protein, and drafted the manuscript. ND carried out the adult injectable RNAi and functional assays. HM conceived of the study, and participated in its design and coordination. All authors read and approved the final manuscript.

\section{References}

I. Fire A, Xu S, Montgomery MK, Kostas SA, Driver SE and Mello CC: Potent and specific genetic interference by double-stranded RNA in Caenorhabditis elegans. Nature 1998, 391:806-8II.

2. Carthew RW: Gene silencing by double-stranded RNA. Curr Opin Cell Biol 200I, 13:244-248.

3. Smalheiser NR, Manev $\mathrm{H}$ and Costa E: RNAi and brain function: was McConnell on the right track? Trends Neurosci 200I, 24:216-218

4. Schmid A, Schindelholz B and Zinn K: Combinatorial RNAi: a method for evaluating the functions of gene families in Drosophila. Trends Neurosci 2002, 25:7I-74.

5. Shi Y: Mammalian RNAi for the masses. Trends Genet 2003, 19:9-12.

6. Dzitoyeva S, Dimitrijevic N and Manev H: Intra-abdominal injection of double-stranded RNA into anesthetized adult Drosophila triggers RNA interference in the central nervous system. Mol Psychiatry 200I, 6:665-670.

7. Dzitoyeva S, Dimitrijevic $\mathrm{N}$ and Manev $\mathrm{H}$ : $\gamma$-Aminobutyric acid B receptor I mediates behavior-impairing actions of alcohol in Drosophila : adult RNA interference and pharmacological evidence. Proc Natl Acad Sci USA 2003, 100:5485-5490.

8. Manev H, Dimitrijevic $\mathrm{N}$ and Dzitoyeva S: Fruit flies as models for neuropharmacological research. Trends Pharmacol Sci 2003, 24:4I-43.

9. Amdam GV, Simones ZL, Guidugli KR, Norberg K and Omholt SW: Disruption of vitellogenin gene function in adult honeybees by intra-abdominal injection of double-stranded RNA. BMC Biotechnol 2003, 3:1.

10. Korneev SA, Kemenes I, Straub V, Staras K, Korneeva El, Kemenes G, Benjamin PR and O'Shea M: Suppression of nitric oxide (NO)dependent behavior by double-stranded RNA-mediated silencing of a neuronal NO synthase gene. J Neurosci 2002, 22:RC227.

II. Song E, Lee SK, Wang J, Ince N, Ouyang N, Min J, Chen J, Shankar P and Lieberman J: RNA interference targeting Fas protects mice from fulminant hepatitis. Nat Med 2003, 9:347-35I.

12. Chen $M-J$ and Lai $Y-L$ : Tachykinin dysfunction attenuates monocrotaline-induced pulmonary hypertension. Toxicol Appl Pharmacol 2003, 187:178-I85.

13. Roignat J-Y, Carre C, Mugat B, Szymczak D, Lepesant J-A and Antoniewski C: Absence of transitive and systemic pathways allows cell-specific and isoform-specific RNAi in Drosophila. RNA 2003, 9:299-308.

14. Van Roessel P, Hayward NM, Barros CS and Brand AH: Two-color GFP imaging demonstrates cell-autonomy of GAL4-driven RNA interference in Drosophila. Genesis 2002, 34:170-173.

15. Choy RK and Thomas JH: Fluoxetine-resistant mutants in C. elegans define a novel family of transmembrane proteins. Mol Cell 1999, 4:143-152.

16. Barker EL, Perlman MA, Adkins EM, Houlihan WJ, Pristupa ZB, Niznik $H B$ and Blakely RD: High affinity recognition of serotonin transporter antagonists defined by species-scenning mutagenesis. An aromatic residue in transmembrane domain I dictates species-selective recognition of citalopram and mazindol. J Biol Chem 1998, 273:19459-19468. 
17. Dzitoyeva S, Dimitrijevic $\mathrm{N}$ and Manev H: Drosophila as a model for discovering novel therapeutic gene targets. Biol Psychiatry 2002, 5 I: I35S.

18. Bourbon HM, Gonzy-Treboul G, Peronnet F, Alin MF, Ardourel C, Benassayag C, Cribbs D, Deutsch J, Ferrer P, Haenlin M, Lepesant JA, Noselli $S$ and Vincent A: A P-insertion screen identifying novel X-linked essential genes in Drosophila. Mech Dev 2002, | | 0:7|-83.

19. Falquet L, Pagni M, Bucher P, Hulo N, Sigrist C], Hofmann K and Bairoch A: The PROSITE database, its status in 2002. Nucleic Acids Res 2002, 30:235-238.

20. Hofmann $K$, Bucher $P$, Falquet $L$ and Bairoch $A$ : The PROSITE database, its status in 1999. Nucleic Acids Res 1999, 27:2 15-219.

21 . Alexandre $C$, Lecourtois $M$ and Vincent J-P: Wingless and Hedgehog pattern Drosophila denticle belts by regulating the production of short-range signals. Development 1999, I 26:5689-5698.

22. Wiellette EL and McGinnis W: Hox genes differentially regulate Serrate to generate segment-specific structures. Development 1999, I 26: 1985-1995.

23. Porter JA, von Kessler DP, Ekker SC, Young KE, Lee JJ and Beachy PA: The product of hedgehog autoproteolytic cleavage active in local and long-range signalling. Nature 1995, 374:363-366.

24. Porter JA, Young KE and Beachy PA: Cholesterol modification of hedgehog signaling proteins in animal development. Science 1996, 274:255-259.

25. Chamoun Z, Mann RK, Nellen D, von Kessler DP, Bellotto M, Beachy PA and Basler K: Skinny Hedgehog, an Acyltransferase required for Palmitoylation and Activity of the Hedgehog Signal. Science 200I, 293:2080-2083.

26. Micchelli CA, The I, Selva E, Mogila $V$ and Perrimon N: Rasp, a putative transmembrane acyltransferase, is required for Hedgehog signaling. Development 2002, I 29:843-85 I.

27. Suzuki Y, Shimozawa N, Imamura A, Fukuda S, Zhang Z, Orii T and Kondo N: Clinical, biochemical and genetic aspects and neuronal migration in peroxisome biogenesis disorders. J Inherit Metab Dis 200I, 24:I5I-I65.

28. Subramani S, Koller A and Snyder WB: Import of peroxisomal matrix and membrane proteins. Annu Rev Biochem 2000, 69:399-418

29. Singh I, Carillo $O$ and Namboodiri A: Isolation and biochemical characterization of peroxisomes from cultured rat glial cells. Neurochem Res 2000, 25:197-203.

30. Megias A, Municio AM and Perez-Albarsanz MA: Biochemistry of development in insects. Triacylglycerol and phosphoglyceride biosynthesys by subcellular fractions. Eur J Biochem 1977, 72:9-16.

31. Guichet A, Wucherpfenning T, Dudu V, Etter S, Wilsch-Brauninger M, Hellwig A, Gonzales-Gaitan M, Huttner WB and Schmidt AA: Essential role of endophilin $A$ in synaptic vesicle budding at the Drosophila neuromuscular junction. EMBO J 2002, 21:|66|-|672.

32. Hannah MJ, Schmidt AA and Huttner WB: Synaptic vesicle biogenesis. Annu Rev Cell Dev Biol 1999, I 5:733-798.

33. Kuhl D and Skehel P: Dendritic localization of mRNAs. Curr Opin Neurobiol 1998, 8:600-606.

34. Whiting $P$ and Dinan L: Formation of apolar ecdysteroid conjugates by ovaries of the house cricket Acheta domesticus in vitro. Biochem J 1988, I 5:95-103.

35. Sambrook J and Russel DW: Molecular Cloning: A Laboratory Manual. Cold Spring Harbor: Cold Spring Harbor Laboratory Press, Cold Spring Harbor 200I.

36. Sullivian W, Ashburner R and Hawley S: Drosophila Protocols. Cold Spring Harbor: Cold Spring Harbor Laboratory Press 2000.
Publish with Biomed Central and every scientist can read your work free of charge

"BioMed Central will be the most significant development for disseminating the results of biomedical research in our lifetime. "

Sir Paul Nurse, Cancer Research UK

Your research papers will be:

- available free of charge to the entire biomedical community

- peer reviewed and published immediately upon acceptance

- cited in PubMed and archived on PubMed Central

- yours - you keep the copyright

Submit your manuscript here:

http://www.biomedcentral.com/info/publishing_adv.asp
BioMedcentral 